TITLE:

\title{
A high temperature superconducting induction/synchronous motor with a ten-fold improvement in torque density
}

\section{$\operatorname{AUTHOR(S):~}$}

Nakamura, T; Matsumura, K; Nishimura, T; Nagao, K; Yamada, Y; Amemiya, N; Itoh, Y; Terazawa, T; Osamura, $\mathrm{K}$

\section{CITATION:}

Nakamura, T ...[et al]. A high temperature superconducting induction/synchronous motor with a ten-fold improvement in torque density. Superconductor Science and Technology 2011, 24(1): 015014.

\section{ISSUE DATE:}

2011-01-01

URL:

http://hdl.handle.net/2433/138653

\section{RIGHT:}

C IOP Publishing 2011; この論文は出版社版でありません。引用の際に は出版社版をご確認ご利用ください。; This is not the published version. Please cite only the published version. 


\title{
A high temperature superconducting induction/synchronous motor with a ten-fold improvement in torque density
}

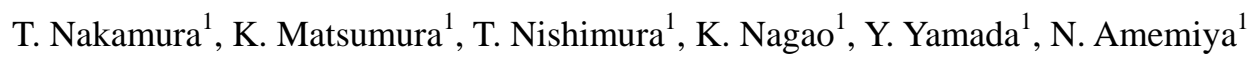

Y. Itoh $^{2}$, T. Terazawa ${ }^{2}$ and K. Osamura ${ }^{3}$

1. Department of Electrical Engineering, Graduate school of Engineering, Kyoto University, 1 Kyoto-Daigaku-Katsura, Nishikyo-Ku, Kyoto 615-8510, Japan

2. IMRA MATERIAL R\&D Co., Ltd, 2-1 Asahi-Machi, Kariya 448-0032, Japan

3. Research Institute for Applied Sciences, 49 Tanaka-Ooi-Cho, Sakyo-Ku, Kyoto 606-8202, Japan

E-mail: tk_naka@ kuee.kyoto-u.ac.jp (Taketsune Nakamura, Kyoto University)

\begin{abstract}
.
In this paper, enhancement of torque density in high temperature superconductor (HTS) induction/synchronous machine is experimentally and theoretically investigated by the use of $\mathrm{Bi}-2223$ windings. Basic structure of this machine is the same as that of a conventional squirrel-cage induction motor, and the secondary windings are replaced by the superconducting tapes. Firstly, quantitative values of the enhanced torque are measured in an experiment using a fabricated motor at $77 \mathrm{~K}$. Then, such torque result is theoretically confirmed based upon the analytical expression, which is derived from the nonlinear electrical equivalent circuit. It is shown that the theoretical result and experimental one agree well each other, and then the torque value drastically increases for more than ten times compared to the conventional induction motor. These results indicate that the compact sized high efficiency HTS motor is possibly realized in simple structure.
\end{abstract}

\section{Introduction}

High Temperature Superconductor (HTS) rotating motor is one of the most possible candidates for the realization of the practical HTS applications. And then, many trials for the developments of such motor by use of the HTS wires have actively been carried out for ship propulsions [1-3], aircraft [4], electric vehicle [5] and so on [6-10]. Most of the above-mentioned HTS machines (except for the reference [3]) are developed with 
the aid of the high magnetic field generation characteristics of the HTS field windings. In other words, so-called "magnetic-loading" is enhanced in such HTS machines.

On the other hand, we have been developing so-called HTS Induction/Synchronous Machine (HTS-ISM) [11-16]. Basic structure of the machine is the same as that of the squirrel-cage induction motor, and the secondary windings are replaced by the HTS wires. Although this is a comparatively simple modification, the HTS-ISM possesses excellent characteristics. One of the most important characteristics is its co-existence of slip and synchronous rotation modes. As is well known, the conventional (normal conducting) induction motor only has the slip mode. When the secondary windings are made of the HTS (zero resistance) wires, on the other hand, the synchronous rotation is possibly realized, by trapping the interlinked magnetic fluxes in such windings. We have firstly reported the no-load rotation characteristics of the HTS-ISM based on the analysis [11] and the experiment [12]. And then, the load characteristics for different HTS cage windings are shown in [13], [14], and [15], respectively. Especially, we have shown the relationship between the mean critical current of the HTS rotor bars and the maximum synchronous torque in [15]. Furthermore, the power generation performance of the HTS-ISM has also been clarified in [16]. Compared to the typical HTS machines [1, 2, 4-10], one can say that so-called "electric-loading" is enhanced for the performance improvement of the HTS-ISM. In other words, large current carrying capability of the HTS rotor bars (not the high magnetic field generation performance) is utilized for such machine. We have to emphasize that DC currents are flowed in the HTS cage windings at the steady-state synchronous rotation mode, and then AC losses are not generated in such windings. Also, the iron-core is utilized in the HTS-ISM and the HTS rotor bars are inserted in the slots of such core, and so we don't need to consider the magnetic field dependency of the HTS rotor bar's critical current, i.e., much magnetic fluxes go through the core not the HTS rotor bars. Also, the rotor currents are induced by the magneto-motive force supplied from the stator, and such currents are comparatively uniform even if the rotor bars are made of stacked HTS tapes. Strictly speaking, the current may still be distributed slightly in the HTS stacked rotor bars, but we have shown that the measured values of the maximum synchronous torque agree well with the theoretical one obtained for the uniform rotor bar current [13-15].

We have also shown that the HTS-ISM is robust against the overload [13-16]. That is, when the overload is applied to the HTS-ISM that rotates at the synchronous speed, such motor can safely keep rotation by changing the rotation mode from the synchronous to the slip for a while. At this rotation mode, the HTS rotor bars, of course, experience the AC loss. It should be noted, however, that this is a kind of fail-safe mode 
for the overload accident, and then continues for very short time.

As is discussed above, the energy conversion efficiency of the HTS-ISM will be very high compared to the conventional (normal conducting) motor, thanks to the steady-state synchronous operation as well as the disappearance of the copper losses in the HTS secondary windings. Furthermore, another important characteristic of such motor is the enhancement of the torque density. As an example, Sumitomo Electric Industries (SEI) in Japan has recently succeeded in the drive of the electric vehicle by means of the claw-pole type superconducting Bi-2223 motor [5]. However, they adopt the transmission gears for the drive of such vehicle in order to obtain adequate traction force. If we can remove such heavy and loss generating gears, i.e., direct drive, then the weight as well as the efficiency of the total system will be drastically improved. This would be realized by increasing the torque density of the HTS motor.

In this study, possible enhancement of the torque density of the HTS-ISM is directly investigated based on the experiment. And then, such torque is theoretically discussed by means of the electrical equivalent circuit that takes into account the nonlinear current transport property of the HTS windings.

\section{Fabrication of HTS-ISM}

\subsection{Target motor}

Detailed explanation of the target motor for the fabrication of the HTS-ISM has already been reported in [11-16]. Then, the basic structure of such motor is concisely explained at this section. Figure 1 (a) shows an outside appearance of the target motor, $200 \mathrm{~mm}$ in length and $170 \mathrm{~mm}$ in diameter. The copper stator windings, those adopts the 3-phase, 4-pole, distributed windings (star connection) are utilized in this study. The effective turn number of the stator windings, $N_{\text {eff }}$, is 26.7. Figure 1 (b) shows a photograph of the rotor core (laminated silicon steel), and the HTS secondary windings are fabricated with the use of such core. The number of the rotor slots is 44 .

\subsection{Design and fabrication of HTS rotor bars}

The maximum synchronous torque, $\tau_{\mathrm{sm}}$, is expressed based on the nonlinear electrical equivalent circuit as follows [11].

$$
\tau_{\mathrm{sm}}=\xi \frac{p}{2} \phi_{s}^{\prime} I_{c}^{\prime}
$$


where, $\xi(=3)$ and $P(=4)$ denote the phase number and the pole number, respectively. As this equation shows, $\tau_{\mathrm{sm}}$ is determined by the primary converted trapped magnetic fluxes, $\phi_{\mathrm{s}}{ }^{\prime}$, and the critical current of one rotor bar, $I_{\mathrm{c}}{ }^{\prime}\left(=I_{\mathrm{c}} / N_{\mathrm{eff}}\right)$. The value of $\phi_{\mathrm{s}}{ }^{\prime}$ is expressed as follows.

$$
\phi_{s}{ }^{\prime}=\frac{\sqrt{V_{1}^{2}-\left[\omega\left(l_{1}+l_{2}{ }^{\prime}\right) I_{c}{ }^{\prime}\right]^{2}}-r_{1} I_{c}{ }^{\prime}}{\omega}
$$

where, $V_{1}, l_{1}+l_{2}{ }^{\prime}(=9.63 \mathrm{mH}), r_{1}(=0.12 \Omega @ 77 \mathrm{~K})$, and $\omega(=2 \pi f ; f$ : primary frequency) are, correspondingly, input phase voltage, total leakage inductance, resistance of the primary windings and the angular frequency. Figure 2 shows the $\tau_{\mathrm{sm}}$ versus $I_{\mathrm{c}}$ curves for different input line voltages at $f=40 \mathrm{~Hz}$, obtained from equations (1) and (2). As can be seen, the curves show the peak because of the decrement of $\phi_{\mathrm{s}}$, i.e., enlargement of voltage drop at the primary resistance and the leakage reactance (see equation (2)). Then, the value of $I_{\mathrm{c}}$ should be less than such peak value for designing the high efficiency machine. Considering the range of the input line voltage between $200 \mathrm{~V}$ and $250 \mathrm{~V}$, the critical current of the rotor bar is designed to be $756 \mathrm{~A}$ (determination of this concrete value will be explained below). As shown by the broken line in figure 2 , the corresponding values of $\tau_{\mathrm{sm}}$ at $f=40 \mathrm{~Hz}$ are, respectively, $60.5 \mathrm{Nm}$ for $200 \mathrm{~V}$ and 83.6 $\mathrm{Nm}$ for $250 \mathrm{~V}$.

Figure 3 (a) shows the schematic diagram of the designed HTS rotor bar. Ten pieces of the DI-BSCCO tapes are bundled and attached to a copper bar, $3.0 \mathrm{~mm}$ in width and $2.0 \mathrm{~mm}$ in thickness, by use of the polyimide tapes. Nominal critical current of such DI-BSCCO tape (2.4 mm in width and $0.2 \mathrm{~mm}$ in thickness) is $75.6 \mathrm{~A} @ 77 \mathrm{~K}$, and then the total critical current of one rotor bar is $756 \mathrm{~A}$ (=75.6 A x10). It should be noted that both ends of the DI-BSCCO tapes are only soldered (soldering area: $10 \mathrm{~mm}$ from the edge of the tape), and the other areas are simply bundled together. As can be seen in the figure, the lengths of the DI-BSCCO tapes are shortened as stacking the tapes from the bottom to the top, in order to increase the soldering area between the rotor bars and the end rings. It is known that the motor's performance is dominated by the current transport property of the HTS rotor bars, which are located in the core slots. In other words, the above-mentioned unequal lengths of the rotor bars will not influence the performance. Figure 3 (b) shows a photograph of fabricated HTS rotor bar.

\subsection{Completion of HTS rotor}


After all rotor bars are installed in the rotor slots (44 slots in this study), both ends of the rotor bars are soldered by winding another type of the DI-BSCCO tapes $(4.3 \mathrm{~mm}$ in width and $0.23 \mathrm{~mm}$ in thickness, critical current: $180 \mathrm{~A} @ 77 \mathrm{~K}$ ) as the end rings. Total turn number of each end-ring is 15 , and then the corresponding critical current is $2700 \mathrm{~A}(=180 \mathrm{~A} \times 15)$. This value is more than 3 times larger than the critical current of one rotor bar. Therefore, we can say that the HTS end-rings are always in the zero resistivity state, no dependence of the rotor bar's state, i.e. zero resistivity state or flux-flow (dissipative) state. Figure 4 (a) shows a photograph of the completed HTS rotor. We can see that the surface of the end-rings is covered with the solder paste. The fabricated HTS rotor is installed in the conventional (copper) stator as shown in figure 4 (b). The air-gap length between the stator and the rotor is $0.3 \mathrm{~mm}$. All lubrication oil of the motor is removed by use of acetone in order to avoid the freeze in liquid nitrogen.

\section{Test method}

\subsection{Bench}

Figure 5 (a) and (b), respectively, illustrate the schematic diagram and the photograph of the test bench. The fabricated HTS-ISM is installed in a metal cryostat, and then immersed in liquid nitrogen. The shaft of the motor is connected to the no-contact torque transducer and the Permanent Magnet (PM) machine (rated power: $30 \mathrm{~kW}$ ), through ferro-fluid (magnetic) seal. The seal is utilized in order to insulate the inner space of the cryostat (cryogenic temperature) from the outside (room temperature), and the gas nitrogen is pushed back into the cryostat for the avoidance of freeze of the seal.

The fabricated HTS-ISM is driven by use of the commercial PWM (Pulse Width Modulation) inverter, and then the frequency fluctuation of the line voltage can be neglected. The rotation speed of the motor is measured by means of the optical tachometer. The PM machine is utilized in generator mode for the application of the mechanical load to the HTS-ISM, and the generated torque is measured by means of the torque transducer. It should be noted that the mechanical oscillation occurs at the rotation speed around $600 \mathrm{rpm}(20 \mathrm{~Hz})$, and so this speed should be avoided for the test.

\subsection{Procedure}

Both of the HTS-ISM and the PM machine are fed by the PWM inverters. The 
wiring diagram of the test system is shown in Figure 6. As can be seen, the DC lines before the IGBT inverter circuits are connected each other. Then, the generated power at the PM machine will circulate to the inverter circuit of the HTS-ISM, by way of the free-wheel diodes of the inverter of the PM machine and the above-mentioned DC lines. In this case, high power test can easily be realized by recycling the generated power of the load (PM) machine, for the excitation of the HTS-ISM. In other words, the 200 V/400 V transformer can supply only the power losses of the motor and the inverter.

\section{Results and discussion}

\subsection{Load test}

The tests are carried out in atmospheric liquid nitrogen $(77 \mathrm{~K})$. The fabricated HTS-ISM is firstly pulled in to be the synchronous rotation with no-load condition, and then the load is gradually applied. It should be noted that the rated torque of the original (aluminum die-casting) rotor at room temperature is about $8 \mathrm{Nm}$, and the diameter of the rotor shaft is $24.0 \mathrm{~mm}$. Then, we must carefully apply the load for the high torque test from the safety reason.

Firstly, we perform the test at the input frequency $f_{1}=40 \mathrm{~Hz}$ and the voltage $V_{1}=210$ $\mathrm{V}$. Then, the quasi-synchronous torque [11] at $70.8 \mathrm{Nm}$ is obtained (The meaning of the "quasi-synchronous torque" is to be explained later). This value is about 8.9 times larger than the rated torque of the original motor. So, we try to further increment of the voltage at $250 \mathrm{~V}$. Figure 7 shows the tested result of the torque vs. slip curve. Here, $s$ is defined as $s=\left(N_{\mathrm{s}}-N\right) / N_{\mathrm{s}}$ with the aid of the synchronous speed $N_{\mathrm{s}}$. The value of $N_{\mathrm{s}}$ is $1200 \mathrm{rpm}$ for $f_{1}=40 \mathrm{~Hz}$. It can be clearly seen that the torque successfully reaches $80.5 \mathrm{Nm}$, even the HTS-ISM rotates at high efficiency quasi-synchronous mode. This value is more than ten times larger, compared to the conventional (normal conducting) motor $(8 \mathrm{Nm})$; because of the characteristics of the proportional shifting, the rated torque of the normal conducting induction motor will be unchanged for the operation frequency. Strictly speaking, this torque is realized at the slip of $0.01(1188 \mathrm{rpm})$. This rotation mode is so-called "quasi-synchronous" mode [11]. If the resistance of the rotor windings is ideally zero, the torque can be obtained with the slip at strictly zero. The actual windings, however, include some resistances due to the solder parts between the HTS rotor bars and the HTS end rings, and then this will result in small slip. Such effect has already been discussed in [16]. The rotation mode, however, is clearly different from the slip mode, because further application of the load occurs the sudden stop. Therefore, we 
can directly show the tremendous increment of the torque density. The output power for this torque is $10.0 \mathrm{~kW}$.

Furthermore, the tested value of the maximum quasi-synchronous torque $(80.5 \mathrm{Nm})$ agrees with the analytical value $83.6 \mathrm{Nm}$ (see figure 2). Analytical value, however, is estimated with the assumption that leakage inductance is the same with that at room temperature. Strictly speaking, this value will change by decreasing the operation temperature, and above assumption may be one of the reasons for the slight discrepancy between the analysis and the test. Therefore, more precise determination of the circuit's parameters is one of our important tasks in future. Anyway, it is shown that we can easily and roughly estimate the torque characteristics by means of commonly utilized electrical equivalent circuit.

\subsection{Validation of relationship between rotor bar's critical current and synchronous torque}

The operation condition of the original (normal conducting) motor is $f_{1}=60 \mathrm{~Hz}$ and $V_{1}=200 \mathrm{~V}$. Then, we also carry out the test for the above condition at $77 \mathrm{~K}$. Figure 8 shows the relationship between the maximum synchronous torques, $\tau_{\mathrm{sm}}$, versus critical current of one rotor bar, $I_{\mathrm{c}, \text { rotor }}$. The solid circle shows the tested value for the fabricated HTS-ISM in this study. Values obtained from the already reported experiments are also plotted as the empty circles (reference numbers are indicated in the figure). As can be seen, the experimental data lie almost on the analytical curve (equations (1) and (2)). This indicates that $\tau_{\mathrm{sm}}$ can be determined from equations (1) and (2), i.e., critical current, no dependence upon the sort of HTS material (BSCCO or YBCO). Strictly speaking, the torque value of the tested results (solid circle) is slightly larger than that of the theoretical curve. One of the reasons for such discrepancies is the difference of the definition of the synchronous torque. As is already explained, although the solid symbol is obtained at the slip of $1188 \mathrm{rpm}$ (quasi-synchronous torque), the theoretical curve is expressed for the genuine critical current (ideal synchronous torque). Unfortunately, the ideal synchronous torque is difficult to be estimated due to the resolution limit of the speed measurement.

\subsection{Further enhancement of torque density}

In section 4.2, the validity of theoretical expression for $\tau_{\mathrm{sm}}$ (equations (1) and (2)) is clarified. Then, further enhancement of $\tau_{\mathrm{sm}}$ is discussed based on such expressions. 
Figure 9 shows the relationship between synchronous torque, $\tau_{\mathrm{sm}}$, versus critical current of one rotor bar, $I_{\mathrm{c} \text {,rotor }}$, at $f_{1}=60 \mathrm{~Hz}$ for different values of input line voltage $\left(V_{1}=200\right.$, 300 and $400 \mathrm{~V}$ ). As shown, $\tau_{\mathrm{sm}}$ can be enormously enhanced by increasing $V_{1}$. Such voltage of the conventional (normal conducting) motor is limited by not only an electric discharge but also the thermal heating. Then, if there are no discharge problems, we can increase the drive voltage of the HTS-ISM, because of its less heating. It should be noted that we also have to care for the magnetic saturation of the iron core for the increment of the voltage. Therefore, we can drastically increase the torque density of the HTS-ISM by optimizing the critical current of one rotor bar and the input line voltage.

\section{Conclusion}

In this paper, enormous enhancement of the torque density was investigated for the high temperature superconductor induction/synchronous motor (HTS-ISM). It was shown that the quasi-synchronous torque of the fabricated HTS-ISM increased at least ten times compared to the rated slip torque of the conventional (normal conducting) induction motor. The obtained quasi-synchronous torque agrees well with the theoretical expression that is formulated based upon the nonlinear electrical equivalent circuit. These results indicate the possibility of the compact sized HTS motor.

\section{Acknowledgements}

This work has been supported in part by Grant-In-Aid for Scientific Research (No. 20560268) in Japan.

\section{References}

1. Snitchler G, Gamble B and Kalsi S S, 2005, IEEE Transactions on Applied Superconductivity, 15, 2, 2206

2. url: http://www.amsc.com/

3. Okazaki T, Sugimoto H and Takeda T, 2006, Power Engineering Society General Meeting, IEEE, 6 pages

4. Masson P J, Tixador P and Luongo C A, 2007, IEEE Transactions on Applied Superconductivity, 17, 2, 1619

5. Hayashi K, 2008, Extended abstracts for International Workshop on Coated Conductors for Applications (CCA'08) 
6. Neumüller H-W, Nick W, Wacker B, Frank M, Nerowski G, Frauenhofer J, Rzadki W and Hartig R, 2006, Superconductor Science and Technology, 19, S114

7. Kummeth P, Ries G, Nick W and Neumüller H-W, 2004, Superconductor Science and Technology, 17, S259

8. Al-Mosawi M K, Beduz C and Yang Y, 2005, IEEE Transactions on Applied Superconductivity, 15, 2, 2182

9. Kwon Y K, Baik S K, Lee E Y, Lee J D, Kim J M, Kim Y C, Moon T S, Park H J, Kwon W S, Hong J P, Jo Y S and Ryu K S, 2007, IEEE Transactions on Applied Superconductivity, 17, 2, 1587

10. Iwakuma M, Hase Y, Satou T, Tomioka A, Konno M, Iijima Y, Saitoh T, Yamada Y, Izumi T, Shiohara Y, 2009, IEEE Transactions on Applied Superconductivity, 19, 3, 1648

11. Morita G, Nakamura T and Muta I 2006, Superconductor Science and Technology, 19,473

12. Nakamura T, Ogama Y, Miyake H, Nagao K and Nishimura T, 2007, Superconductor Science and Technology, 20, 911

13. Nakamura T, Nishimura T, Nagao K, Matsumura K and Ogama Y, 2008,

Proceedings of XVIII International Conference on Electrical Machines (ICEM'08), September 6-9, 2008, Vilamoura, Portugal, ID. 1278

14. Nagao K, Nakamura T, Nishimura T, Ogama Y, Kashima N, Nagaya S, Suzuki K, Izumi T and Shiohara Y, 2008, Superconductor Science and Technology, 21, $015022(5 \mathrm{pp})$

15. Nakamura T, Nagao K, Nishimura T, Ogama Y, Kawamoto M, Okazaki T, Ayai N and Oyama H, 2008, Superconductor Science and Technology, 21, 085006(5pp)

16. Nakamura T, Ogama Y, Matsumura K, Nishimura T, Nagao K, Kashima N and Nagaya S, 2009, Journal of the Cryogenic Society of Japan (in Japanese), 44, 3, 112 


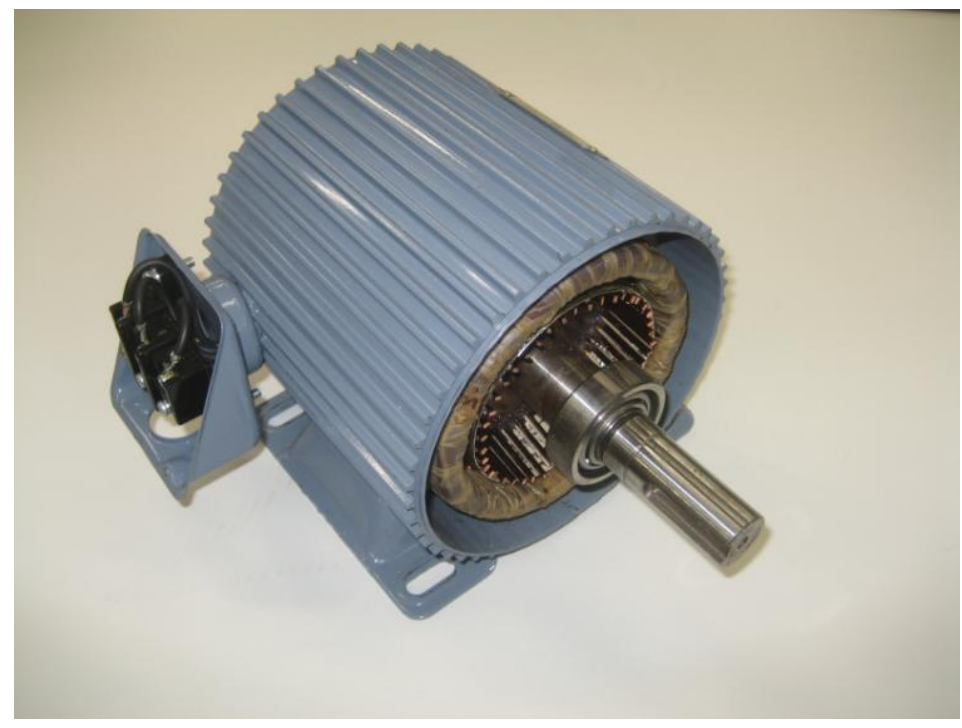

(a) Outside appearance

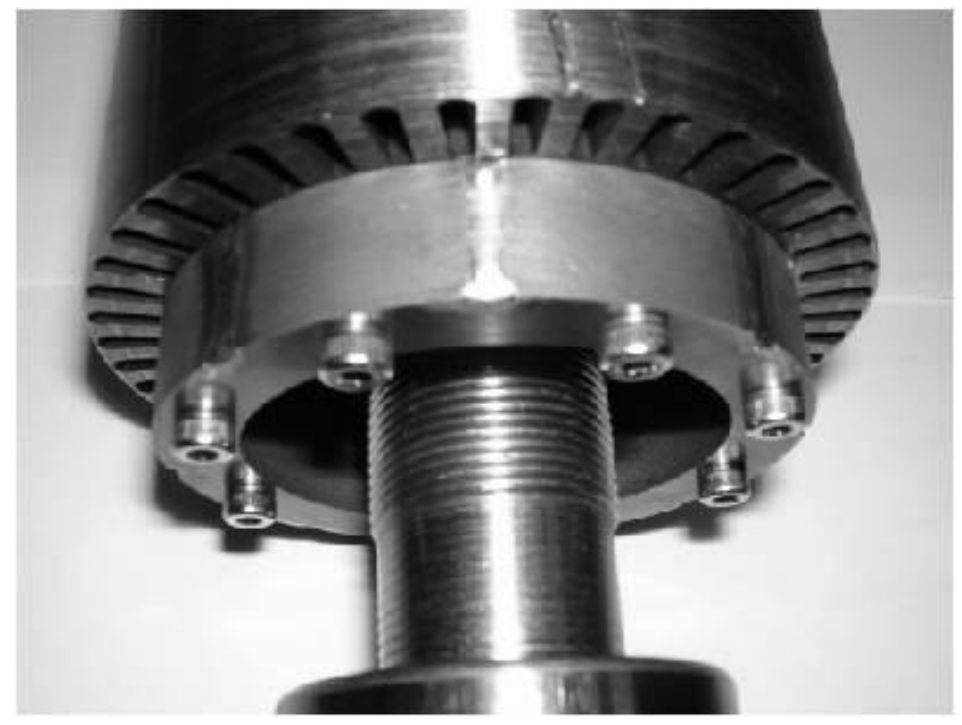

(b) Rotor core

Figure 1 Photographs of target motor 


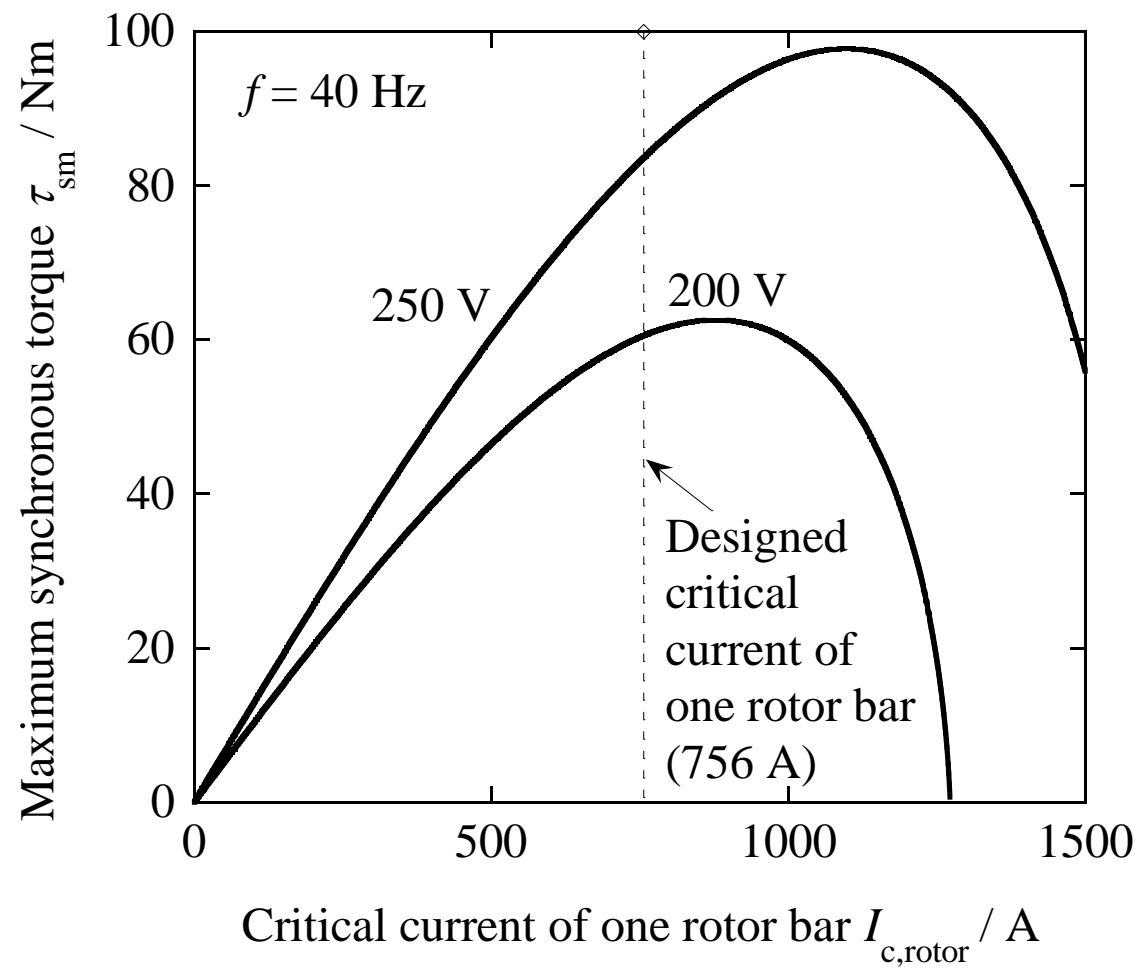

Figure 2 Maximum synchronous torque, $\tau_{\mathrm{sm}}$, versus critical current of one rotor bar, $I_{\mathrm{c}, \text { rotor, }}$, curves plotted for different input voltages at $f=40 \mathrm{~Hz}$. The curves are obtained from equations (1) and (2). 


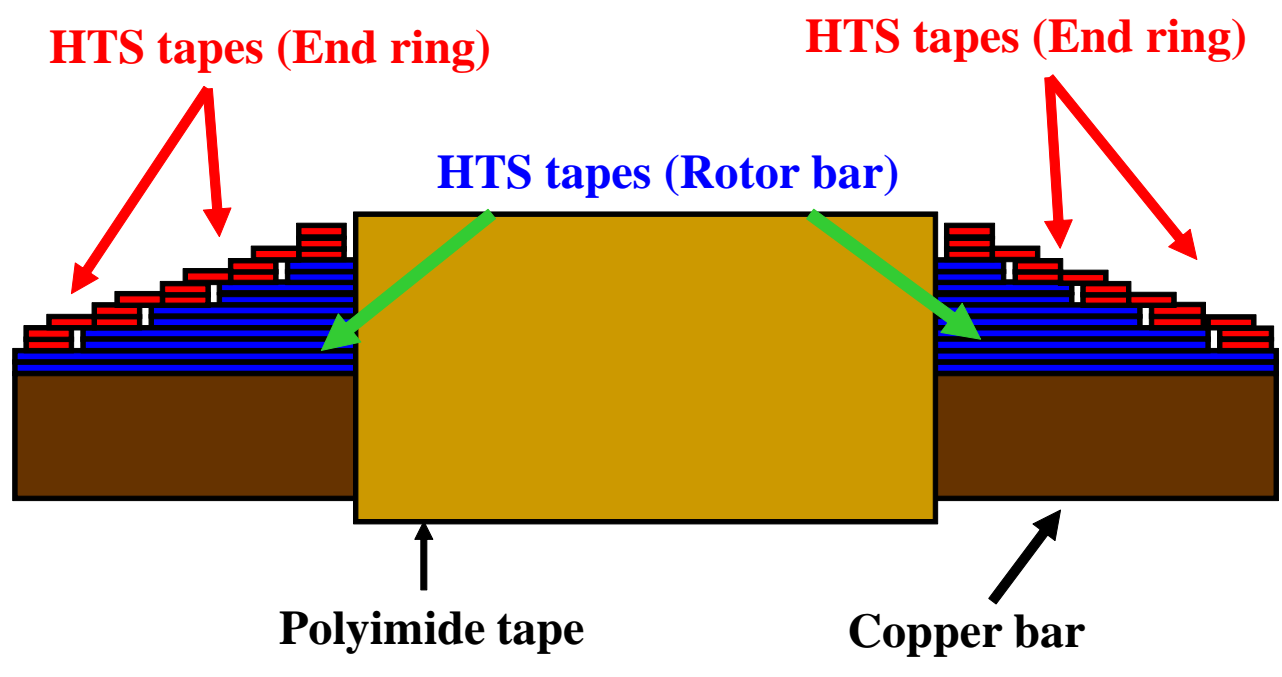

(a) Schematic diagram

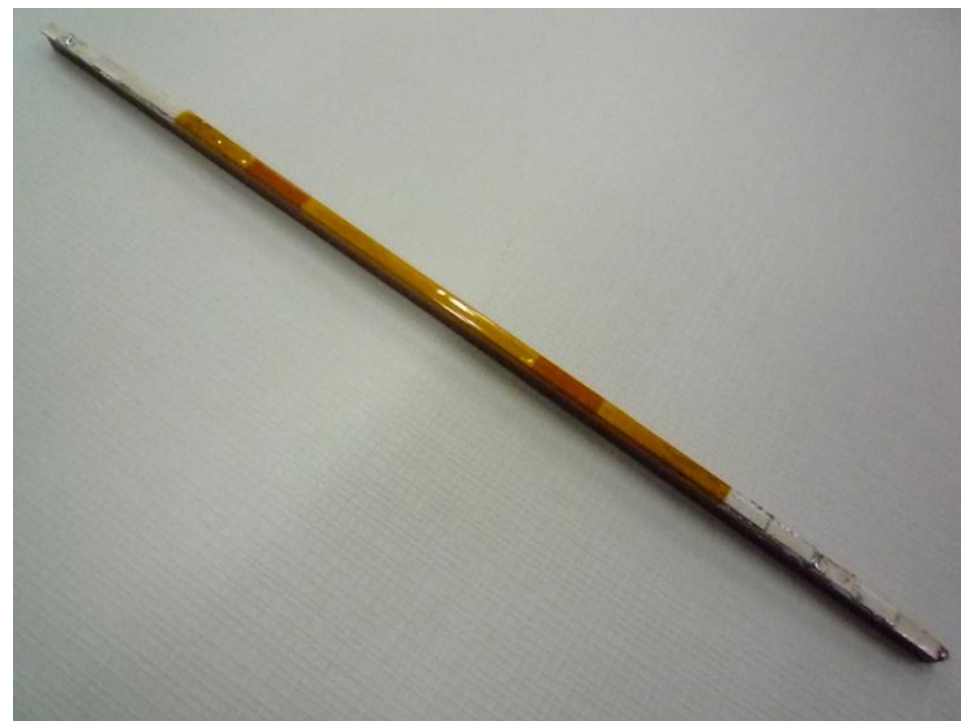

(b) Photograph

Figure 3 Structure of a HTS rotor bar 


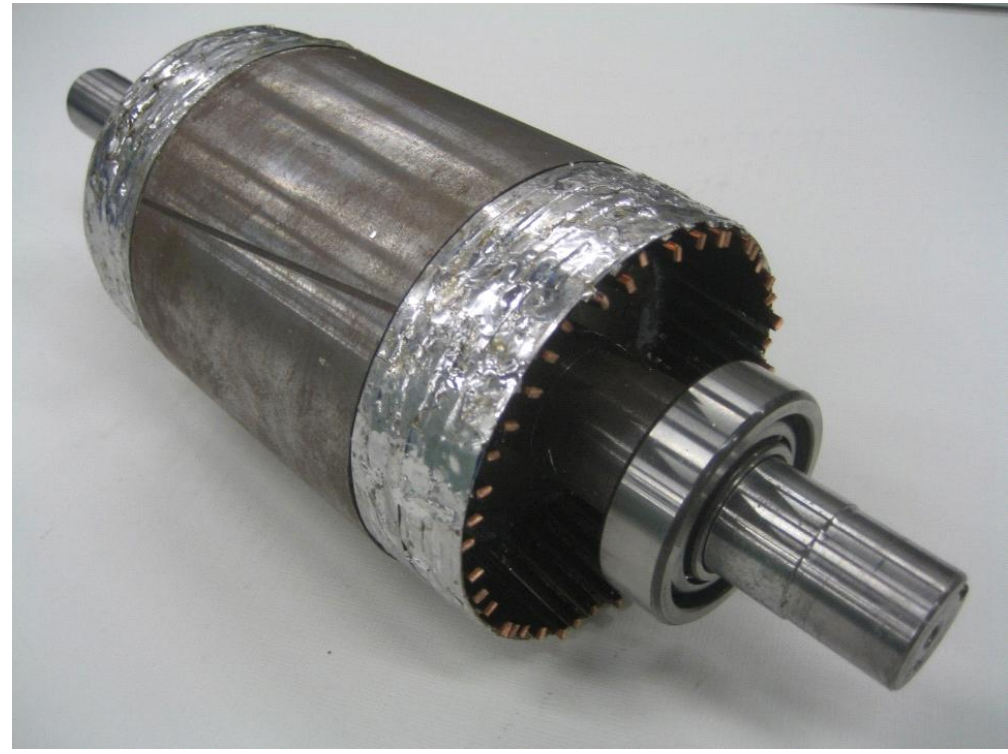

(a) Rotor

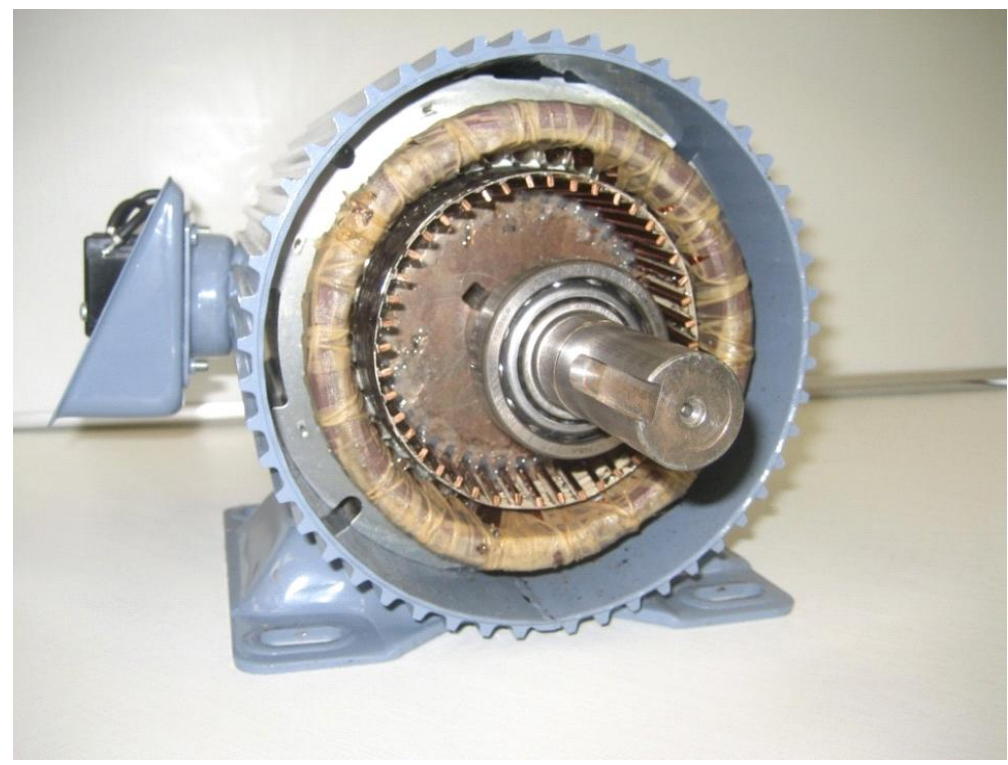

(b) Rotor in the copper stator

Figure 4 Photographs of fabricated high torque density HTS-ISM 


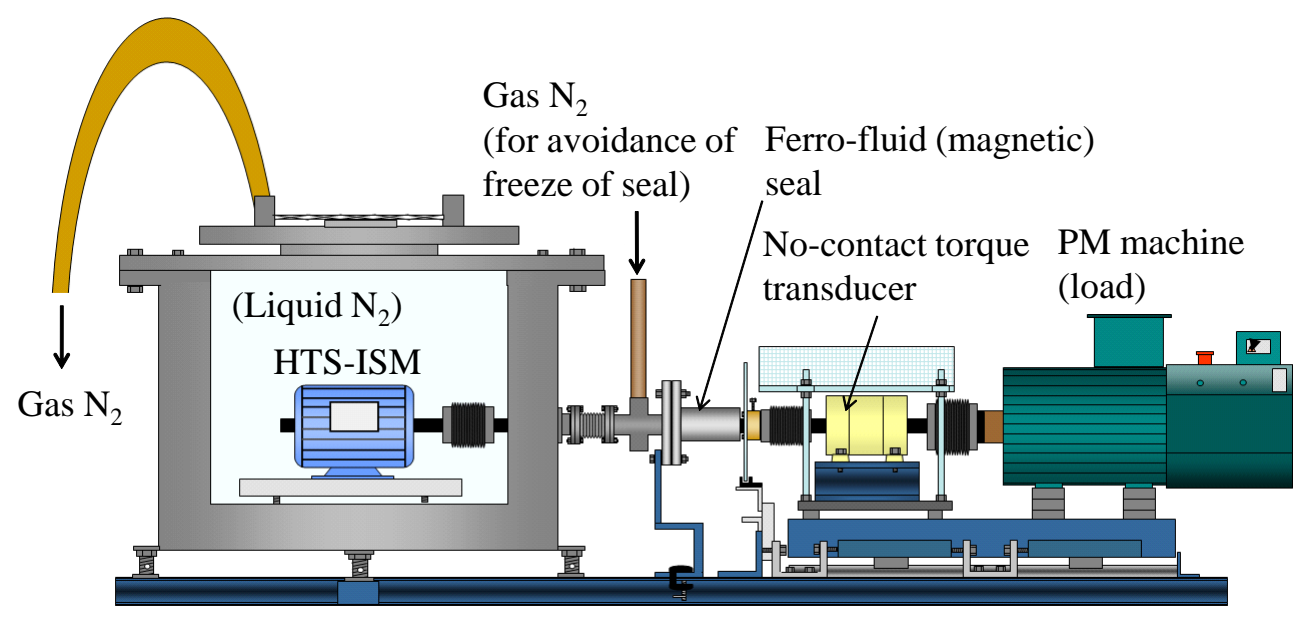

(a) Schematic diagram

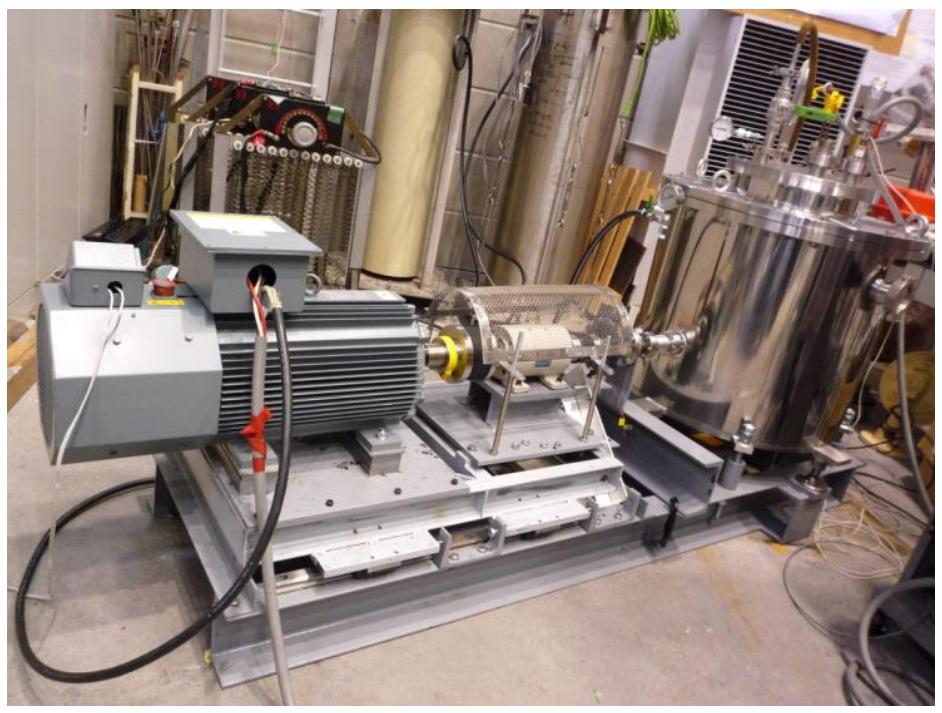

(b) Photograph

Figure 5 Test bench. The fabricated HTS-ISM is installed in the metal cryostat that contains liquid nitrogen. Load is applied by means of the Permanent Magnet (PM) machine (rated power: $30 \mathrm{~kW}$ ). The ferro-fluid (magnetic) seal is for the insulation of the inside of the cryostat from the outside. Gas nitrogen is pushed back into the cryostat for the avoidance of freeze of the seal. 


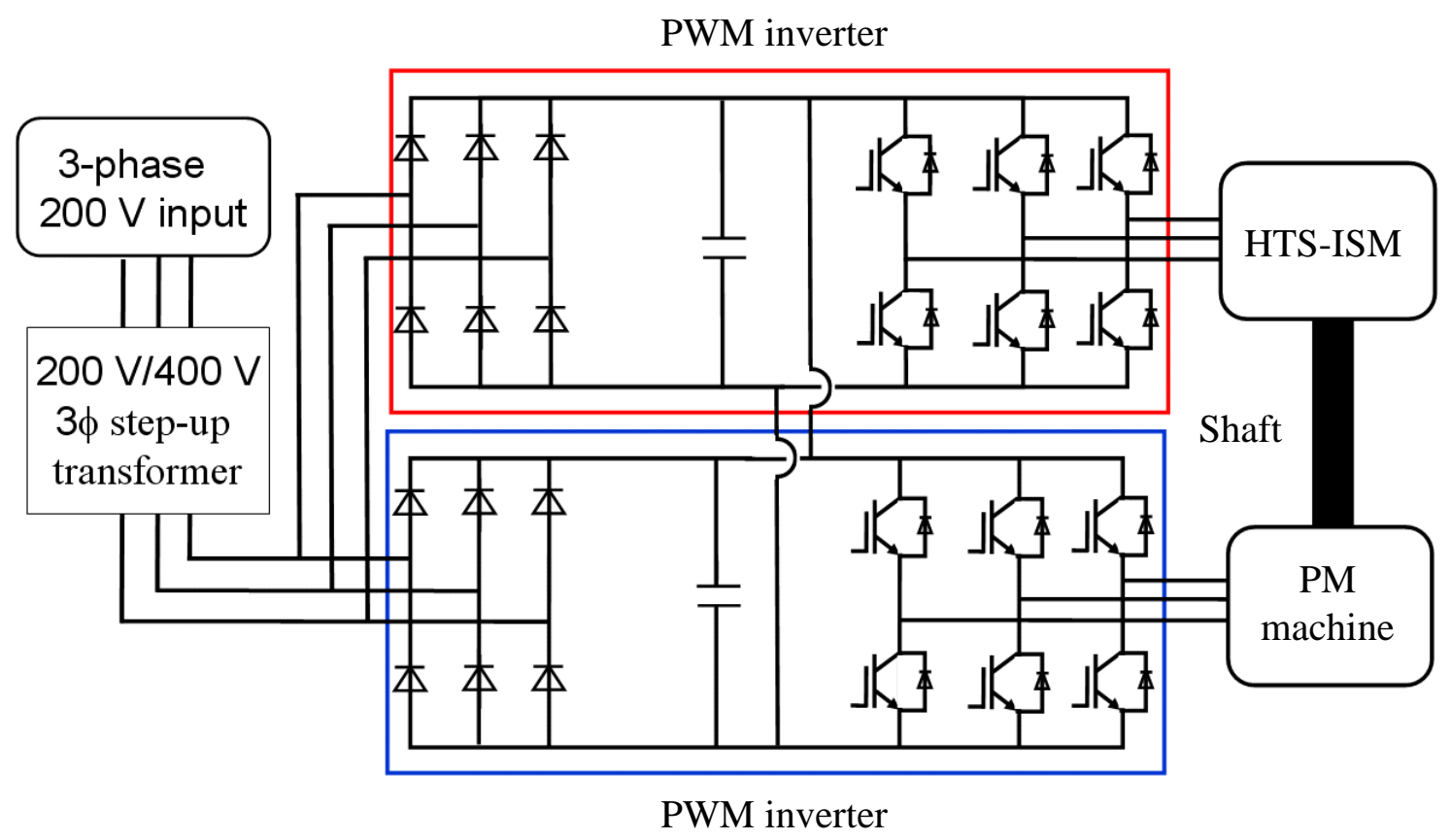

Figure 6 Wiring diagram of the test system 


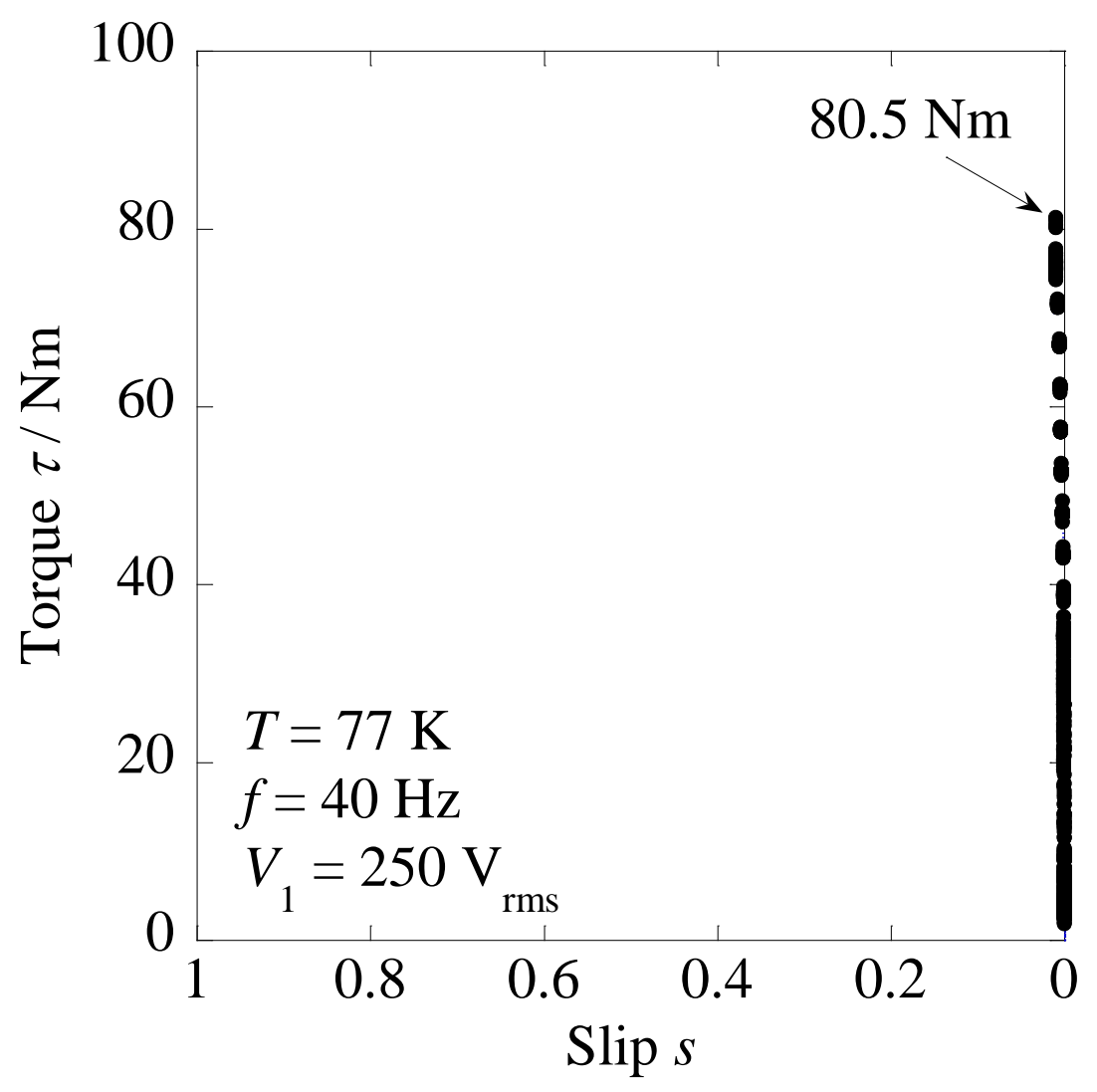

Figure 7 Load test result at $77 \mathrm{~K}$ (input frequency $f_{1}: 40 \mathrm{~Hz}$, input voltage $V_{1}: 250 \mathrm{~V}_{\text {rms }}$ ) 


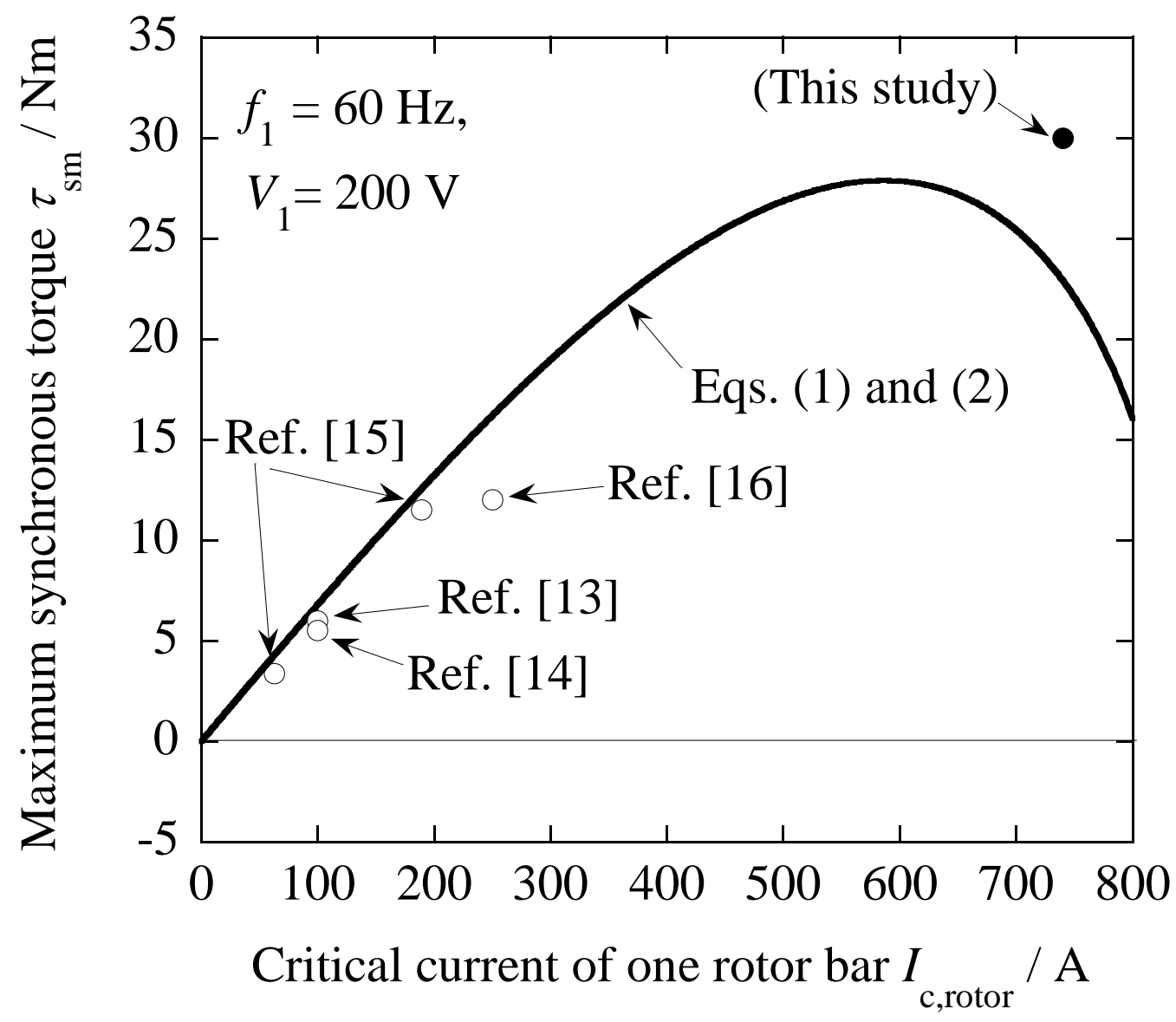

Figure 8 Relationship between synchronous torque, $\tau_{\mathrm{sm}}$, versus critical current of one rotor bar, $I_{\mathrm{c}, \text { rotor }}$, at $f_{1}=60 \mathrm{~Hz}$ and $V_{1}=200 \mathrm{~V}$. The solid circle shows the tested value in this study. The empty circles are obtained from the already reported experiments for the same condition (reference numbers are indicated in the figure). 


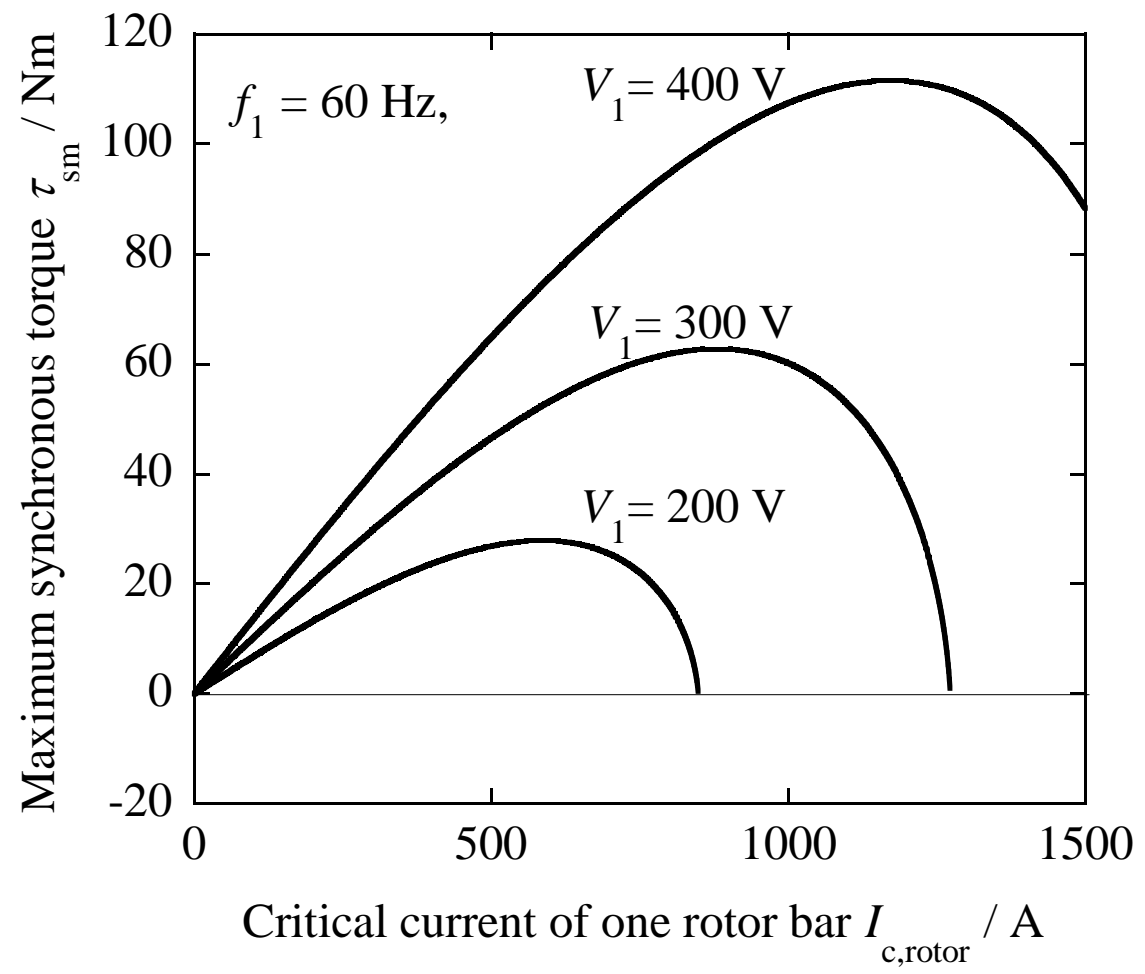

Figure 9 Relationship between synchronous torque, $\tau_{\mathrm{sm}}$, versus critical current of one rotor bar, $I_{\mathrm{c}, \text { rotor }}$, at $f_{1}=60 \mathrm{~Hz}$ for different values of input line voltage $\left(V_{1}=200,300\right.$ and $400 \mathrm{~V})$. Curves are obtained from equations (1) and (2). 